\title{
A two-stage, guarded inductive voltage divider with small ratio errors for coaxial bridge applications
}

\author{
Gregory A. Kyriazis ${ }^{1}$, J. Angel Moreno ${ }^{2}$, Jürgen Melcher ${ }^{3}$ \\ ${ }^{1}$ Instituto Nacional de Metrologia, Qualidade e Tecnologia, Av. Nossa Senhora das Graças, 50, 25250-020, Duque de Caxias, RJ, Brazil \\ ${ }^{2}$ Centro Nacional de Metrología, km 4.5 carretera a los Cués, Municipio del Marqués, CP 76900, Querétaro, Mexico \\ ${ }^{3}$ Physikalisch-Technische Bundesanstalt, Bundesallee 100, 38116 Braunschweig, Germany
}

The traceability chain to derive the capacitance unit from the quantum Hall resistance comprises some coaxial bridges. These bridges employ a main two-stage inductive voltage divider to provide the voltage ratio needed. One such divider has been recently constructed and calibrated at Inmetro. The design techniques responsible for the small ratio errors of the device and the calibration method employed are both detailed. The new divider was installed in Inmetro's two terminal-pair coaxial capacitance bridge with significant improvements in the bridge resolution and accuracy.

Keywords: Capacitance; coaxial bridges; inductive voltage dividers; traceability chain; calibration; metrology

Citation: Gregory A. Kyriazis, J. Angel Moreno, Jürgen Melcher, A two-stage, guarded inductive voltage divider with small ratio errors for coaxial bridge applications, Acta IMEKO, vol. 1, no. 1, article 11, July 2012, identifier: IMEKO-ACTA-01(2012)-01-11

Editor: Pedro Ramos, Instituto de Telecomunicações and Instituto Superior Técnico/Universidade Técnica de Lisboa, Portugal

Received January $9^{\text {th }}, 2012$; In final form May 17 ${ }^{\text {th }}, 2012$; Published July 2012

Copyright: (C) 2012 IMEKO. This is an open-access article distributed under the terms of the Creative Commons Attribution 3.0 License, which permits unrestricted use, distribution, and reproduction in any medium, provided the original author and source are credited

Funding: This work was supported by Instituto Nacional de Metrologia, Qualidade e Tecnologia (Inmetro), Brazil

Corresponding author: Gregory A. Kyriazis, e-mail: gakyriazis@inmetro.gov.br

\section{INTRODUCTION}

The traceability chain to derive the capacitance unit from the quantized Hall resistance comprises a few coaxial bridges: a 1:-1 ratio bridge, a 10:-1 ratio bridge, a quadrature bridge and an inductive voltage divider (IVD) calibration bridge. In fact only three bridges are necessary as a 1:-1 ratio bridge is easily changed to a 10:-1 ratio bridge by a cable rearrangement. All these bridges can use the same isolation transformer and main IVD [1]-[3].

The main IVD to be used in coaxial ratio bridges [4] should be constructed to provide an overall bridge uncertainty at 1:-1 and 10:-1 ratios (at $1 \mathrm{kHz}$ and $1.592 \mathrm{kHz}$ ) of a few parts in $10^{8}$. This requires the use of special guarding and two-stage techniques typically adopted in the $10-100 \mathrm{kHz}$ range [5].

A similar IVD had been constructed previously during the development of Inmetro's two terminal-pair coaxial capacitance bridge [6][7]. This bridge has been in operation since 2005. The old IVD design details and calibration results had been reported in [8]. The new IVD discussed here was completely constructed at Inmetro and presents much smaller ratio errors than the previous one. This work benefitted from the technical expertise of Centro Nacional de Metrología (CENAM) and PhysikalishTechnische Bundesanstalt (PTB).
The coaxial capacitance bridge construction details are reviewed in section 2 . The corresponding measurement model and the cable effects are respectively analyzed in sections 3 and 4. Section 5 presents the construction details of the new IVD and the design changes that we believe were responsible for the results obtained. The IVD calibration is discussed in section 6 . The old IVD was replaced by the new one in the coaxial capacitance bridge and the overall bridge uncertainty was reevaluated as reported in section 7 . The conclusions are drawn in section 8 .

\section{TWO TERMINAL-PAIR COAXIAL CAPACITANCE BRIDGE}

The bridge design is originally from PTB and is similar to that adopted by CENAM [9]. Both Inmetro and CENAM participated successfully with similar bridges in an international comparison on capacitance (SIM.EM-K4, SIM.EM-S4 and SIM.EM-S3 [10]) among several national metrology institutes from the Inter-American Metrology System (SIM).

The capacitance bridge uses a two terminal-pair coaxial design [4]. One way of looking at a coaxial bridge is to see it as two superposed networks (Figure 1). The first of these consists of straightforward meshes of components and the interconnecting wires between them. The second network comprises the shields of the components and the outer, coaxial shield of the connecting cables. The configurations of the two 


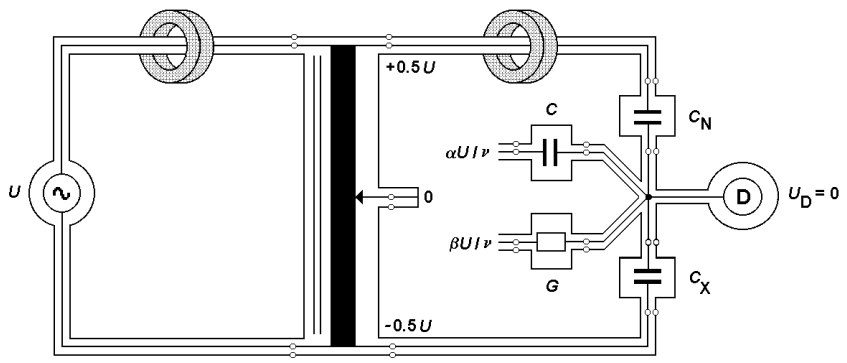

Figure 1. Simplified scheme of the two terminal-pair coaxial capacitance bridge.

networks are identical and by providing every mesh with an equalizing device, the current in the outer shield is constrained to be equal in magnitude and shifted $180^{\circ}$ to the current in the components and central conductors. The current in any cable as a whole is zero and no external magnetic field is created. The second network of shields and cable outer conductors has low impedance and it is all at nearly the same potential, so that there is no significant external electric field. This construction has the further advantage that such networks do not respond to fields from external sources. Otherwise, the bridge balance conditions could be affected.

Current equalization is achieved by threading a coaxial cable through a high permeability (typically supermalloy) toroidal core so that core and cable act as a 1:-1 transformer [11][12]. Usually, the impedance of the outer conductor is several orders of magnitude smaller than the impedance of the inner conductor (which includes impedance standards, transformers, etc.). A current equalizer has therefore no direct effect on the current flowing along the inner conductor; it just gives rise to an equal current flowing along the outer conductor which is supplied from the same source as the inner conductor. To achieve equal return currents in the whole bridge network, every independent mesh of the bridge network must be provided with one current equalizer in a way that every bridge component is connected to the central ground point of the bridge with just one path without current equalizer. This central point is connected to earth ground.

A simplified scheme of a two terminal-pair coaxial bridge for comparing two standard capacitors of the same nominal value $\left(C_{\mathrm{N}}\right.$ and $\left.C_{\mathrm{X}}\right)$ is shown in Figure 1. $C_{\mathrm{X}}$ is the capacitor under calibration and $C_{\mathrm{N}}$ is the reference standard. The current equalizers are also shown in the figure.

The main IVD operates with a voltage $U$ across the taps. Its actual ratio deviates from the nominal 1:-1 ratio by a small complex amount. Further, the two capacitances are not ideal and do not have precisely the same value. The complex voltage $U_{\mathrm{D}}$ detected at the node between the two capacitances is therefore not null. The real part of this voltage is then compensated by injecting an adjustable in-phase current. This is done by applying an adjustable voltage $\alpha U / v$ to capacitor $C$. Likewise, the imaginary part is compensated by injecting an adjustable quadrature current. This is done by applying an adjustable voltage $\beta U / v$ to conductance $G$. When the detector voltage is nullified in this way, we obtain the in-phase balance equation

$C_{\mathrm{X}}=C_{\mathrm{N}}+\left(\alpha_{1}-\alpha_{2}\right) \frac{C}{v}+\left(\beta_{1}-\beta_{2}\right) \frac{C^{\prime}}{v}$,

where $C^{\prime}$ is the parasitic capacitance (not shown in the figure) that shunts the conductance $G$. The dividing factors $\alpha_{1}$ and $\beta_{1}$ are obtained by balancing the bridge with the capacitors $C_{\mathrm{N}}$ and $C_{\mathrm{X}}$ positioned as shown in Figure 1, and $\alpha_{2}$ and $\beta_{2}$ are obtained by rearranging the cables so that $C_{\mathrm{N}}$ and $C_{\mathrm{X}}$ are interchanged. The complex ratio error of the main IVD is cancelled by this technique.

The constructive details of the bridge built at Inmetro are discussed in the sequel.

The detailed scheme of the capacitance bridge is shown in Figure 2. The current equalizers are shown as black rectangles

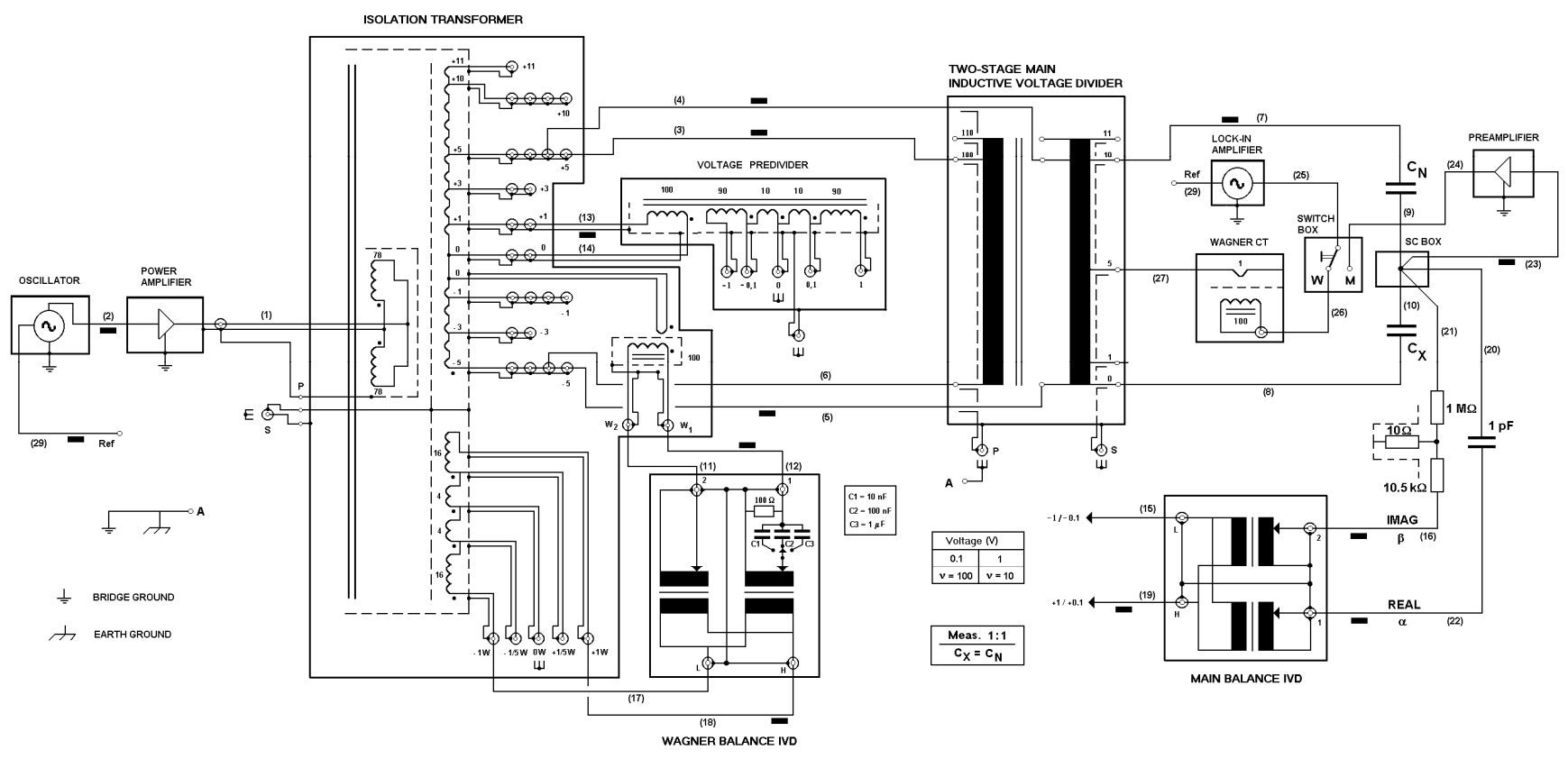

Figure 2. Detailed scheme of the coaxial capacitance bridge (original design from PTB). 
(for clarity, we preferred not to draw the coaxial cable shields). The two terminal-pair coaxial ratio bridge operates at $1 \mathrm{kHz}$ and $1.592 \mathrm{kHz}$ and compares decadic capacitors in the range from $10 \mathrm{pF}$ to $1 \mathrm{nF}$ at $1:-1,10:-1$ and 1:-10 ratios. The scheme of the 1:-1 ratio bridge is shown in Figure 2. A 1:-1 ratio bridge is easily changed to a 10:-1 ratio bridge by a simple cable rearrangement (the corresponding scheme of the 10:-1 ratio bridge is shown in [6]).

The bridge comprises an isolation transformer, a two-stage main IVD, a voltage predivider, a T-network box, a switch box, a short-circuit box, and a Wagner current transformer. The following commercial equipment complement the bridge: an ultra-pure sinusoidal oscillator, a wideband power amplifier, a low-noise preamplifier, a lock-in amplifier, a $1 \mathrm{pF}$ fused-silica standard capacitor and two coaxial, double, six-decade IVDs. A photo of the capacitance bridge is shown in Figure 3.

The isolation transformer is used to isolate the bridge from the mains. The two-stage main IVD is constructed to provide an uncertainty in 1:-1 and 10:-1 ratios of a few parts in 108. Both the isolation transformer and the main IVD have a flexible design that allows their use in other bridges of the aforementioned traceability chain. The specific design and construction details of these devices were published in [13][8].

The power amplifier is cascaded to the sinusoidal oscillator to apply the voltage required to the isolation transformer primary taps, so that up to $U=200 \mathrm{~V}$ is available across the +5 and -5 secondary taps (worst case when two $10 \mathrm{pF}$ capacitors are compared for maintenance of the unit). The voltage $U$ depends on the bridge ratio and the standard capacitor value (see Table 2 in the next section).

Table 1 lists the values of voltage and frequency which are recommended for the whole chain from $10 \mathrm{pF}$ to $1 \mathrm{nF}$. The voltages applied to the standards decrease by a factor of 10 for
Table 1. Voltage applied to standard capacitors.

\begin{tabular}{ccc}
\hline $\begin{array}{c}\text { Standard } \\
(\mathrm{pF})\end{array}$ & $\begin{array}{c}\text { Frequency } \\
(\mathbf{H z})\end{array}$ & $\begin{array}{c}\text { Voltage } \\
(\mathbf{V})\end{array}$ \\
\hline 10 & 1000 & 100 \\
100 & 1000 & 10 \\
1000 & 1000 and 1592 & 1 \\
\hline
\end{tabular}

each 10:-1 ratio step in the chain avoiding corrections due to voltage dependence of the standards (that of the IVD ratio error is negligible). The transition in frequency from $1 \mathrm{kHz}$ to $1.592 \mathrm{kHz}$ is necessary for the traceability chain to derive the capacitance unit from the quantum Hall resistance. It is made with the standard which has the lowest frequency dependence, namely, the $1 \mathrm{nF}$ capacitor. The voltage choice ultimately means that the current flowing through the standards being compared is always kept at approximately $6.3 \mu \mathrm{A}$ at $1 \mathrm{kHz}$ (or $10 \mu \mathrm{A}$ at $1.592 \mathrm{kHz}$ ).

The main balance voltage is derived from the voltage across the +1 and 0 taps of the isolation transformer secondary winding and reduced by the 10:1 voltage predivider. The resulting voltages at the \pm 0.1 taps of the voltage predivider are applied to variable impedances $(1 \mathrm{pF}$ fused silica capacitor and a T-network box cascaded to coaxial, double, six-decade IVDs), thus generating the in-phase and quadrature main balance currents, respectively. The T-network box is built with metalfilm resistors.

The short-circuit box is a multiport connector in which the inners are brought together at a point, as are the outers. A suitable construction is illustrated in [4] where the inners are soldered symmetrically to a disc. The short-circuit box receives the currents flowing through the standards being compared and the in-phase and quadrature main balance currents. It has also

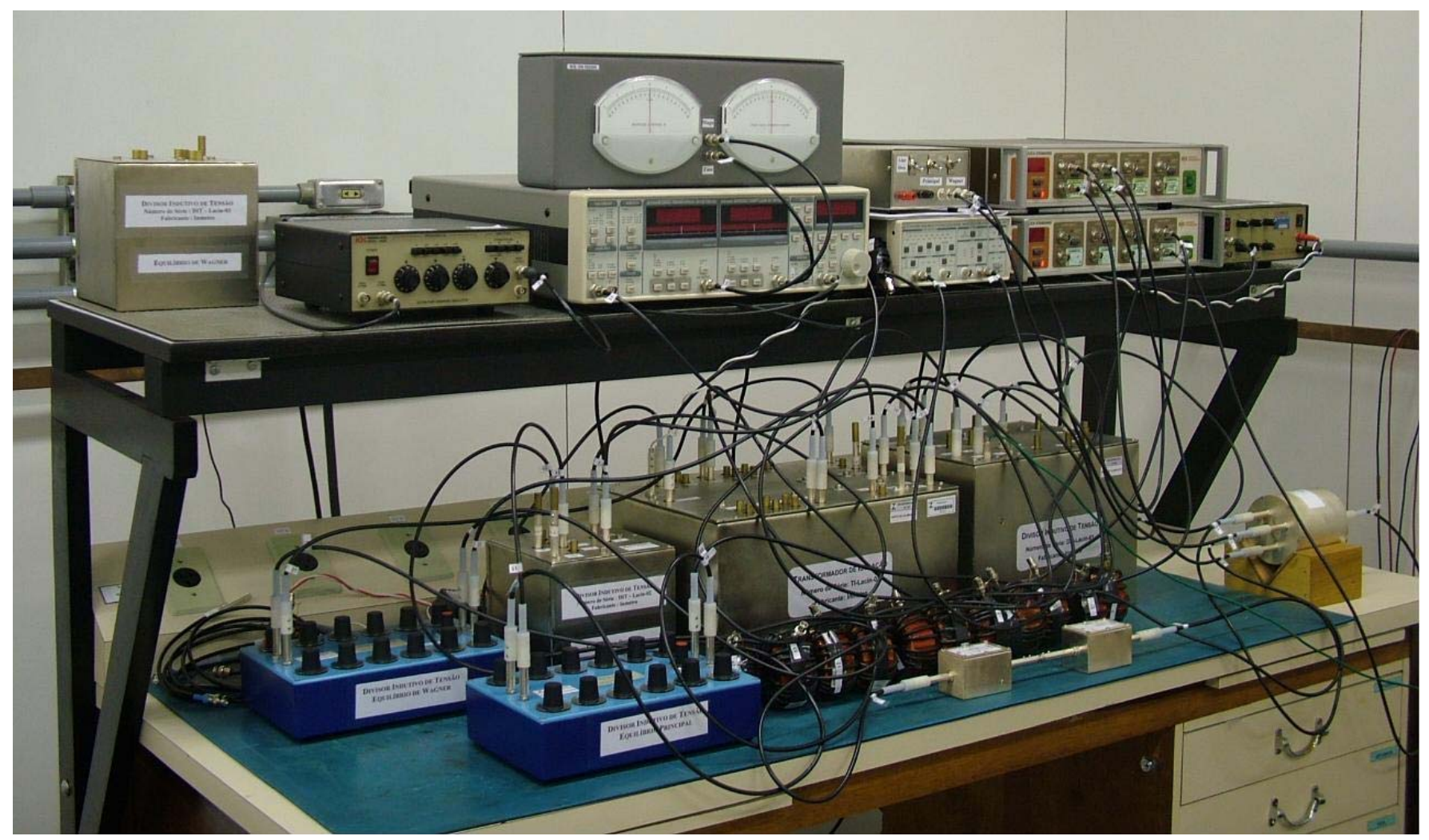

Figure 3. Inmetro's two terminal-pair coaxial capacitance bridge. 
Table 2. Total applied voltage $U$.

\begin{tabular}{ccc}
\hline $\begin{array}{c}\text { Standard } \\
\text { (pF) }\end{array}$ & $\begin{array}{c}\text { Bridge } \\
\text { Ratio }\end{array}$ & $\begin{array}{c}\text { Voltage } \\
\text { (V) }\end{array}$ \\
\hline 10 & $1:-1$ & 200 \\
10 & $10:-1$ & 110 \\
100 & $1:-1$ & 20 \\
100 & $10:-1$ & 11 \\
1000 & $1:-1$ & 2 \\
\hline
\end{tabular}

an output port for voltage monitoring.

The main balance is adjusted by monitoring the voltage at the short-circuit box while changing the impedances connected to the \pm 0.1 taps of the voltage predivider. The low-noise preamplifier is cascaded to the lock-in amplifier to monitor the balance voltage. With the preamplifier gain set to $10^{3}$, we have been able to balance the bridge so that the lock-in amplifier readings are within $\pm 20 \mu \mathrm{V}$.

The isolation transformer has a separate secondary winding for the Wagner balance [13]. This balance is done first (the battery-operated switch box is used to select the balances to be monitored). We have verified that this balance is crucial to the accuracy of the main balance. The voltage across the $\pm 1 \mathrm{~W}$ taps of this separate winding is applied to coaxial, double, sixdecade IVDs with selectable fixed impedances and the generated current is injected in the isolation transformer zero tap connection to ground through an 100:1 injection transformer (installed inside the isolation transformer). This changes the potential between the zero tap and ground. The current in tap terminal 5 of the main IVD is changed accordingly. The Wagner balance is adjusted by monitoring the current in tap terminal 5 with the 1:100 Wagner current transformer while changing the settings of the Wagner balance IVDs. We have been able to balance the Wagner network so that the lock-in amplifier readings are within $\pm 5 \mu \mathrm{V}$.

\section{MEASUREMENT MODEL}

The simplified scheme of the capacitance bridge is shown in Figure 4. The main IVD operates with a voltage $U$ across the 0 and 10 taps for the 1:-1 ratio or across the 0 and 11 taps for the 10:-1 (or 1:-10) ratio (see Figure 2). The voltage value depends on the bridge ratio and the standard capacitor value (Table 2). The nominal ratio of the main IVD is $D=1 / 2$ for the $1:-1$ ratio bridge and $D=1 / 11$ for the $10:-1$ (and $1:-10$ ) ratio bridge. The value of $1 / v$ ratio depends on the bridge ratio and the voltage predivider ratios (Table 3). For instance, for a 1:-1 ratio bridge, the isolation transformer ratio at its +1 secondary tap is $1 / 10$. The voltage predivider ratio at its +0.1 tap (typically used) is $1 / 10$. The value of $1 / v$ ratio in this case is therefore $1 / 100$. The resulting dividing factors of the bridge main balance are $\alpha=(a-0.5) / 0.5$ and $\beta=(b-0.5) / 0.5$, where $a$ and $b$ are the settings of each coaxial six-decade main balance IVD. $C_{\mathrm{N}}$ (and $G_{\mathrm{N}}$ ) is the known capacitance (and conductance) of the standard capacitor, and $C_{\mathrm{X}}$ (and $G_{\mathrm{X}}$ ) is the unknown capacitance (and conductance) of the capacitor under calibration. $C$ is the $1 \mathrm{pF}$ fused-silica standard capacitor. $G$ and $C^{\prime}$ are the conductance and parasitic capacitance, respectively, of the T-network box (with connecting cables), measured with a commercial capacitance bridge.
Table 3. Value of $v$.

\begin{tabular}{ccc}
\hline Predivider ratio & $\begin{array}{c}\text { Bridge } \\
\text { ratio }\end{array}$ & $v$ \\
\hline $10: 1$ & $1:-1$ & 100 \\
$10: 1$ & $10:-1$ & 110 \\
$1: 1$ & $1:-1$ & 10 \\
$1: 1$ & $10:-1$ & 11 \\
\hline
\end{tabular}

The ratio error is here expressed as a fraction of unit. In this case, the IVD ratio is expressed as a sum of the nominal ratio $D$ and the complex ratio error $\varepsilon=k^{\prime}+j k^{\prime \prime}$ ( $k^{\prime}$ and $k^{\prime \prime}$ are respectively the in-phase and quadrature components), that is

$$
U_{0.1-0} / U_{1.1-0}=D+\varepsilon=D+k^{\prime}+j k^{\prime \prime} \text {. }
$$

The main balance is obtained when

$\mathbf{I}_{\mathrm{N}}+\mathbf{I}_{\mathrm{X}}+\mathbf{I}_{\mathrm{B}}=\mathbf{I}_{\mathrm{M}}=0$.

The balance equation for the 1:-1 ratio is given by (1), which is reproduced here for the reader convenience,

$$
C_{\mathrm{X}}=C_{\mathrm{N}}+\left(\alpha_{1}-\alpha_{2}\right) \frac{C}{v}+\left(\beta_{1}-\beta_{2}\right) \frac{C^{\prime}}{v} \text {. }
$$

The dividing factors $\alpha_{1}$ and $\beta_{1}$ are obtained by balancing the bridge with the capacitors positioned as shown in Figure 4, and $\alpha_{2}$ and $\beta_{2}$ are obtained by rearranging the cables so that the capacitors are in the reversed position. As mentioned before the complex ratio error of the main IVD is cancelled by this technique.

However, it is interesting for quality control purposes to compute the in-phase and quadrature components of the ratio error of the main IVD for the 1:-1 ratio, that is

$$
\begin{aligned}
& k^{\prime}=\frac{1}{4 v}\left[\frac{C}{C_{\mathrm{N}}}\left(\alpha_{1}+\alpha_{2}\right)+\frac{C^{\prime}}{C_{\mathrm{X}}}\left(\beta_{1}+\beta_{2}\right)\right] \\
& k^{\prime \prime}=-\frac{G}{4 \omega v C_{\mathrm{N}}}\left(\beta_{1}+\beta_{2}\right)
\end{aligned}
$$

where $\omega$ is the angular frequency.

The corresponding balance equation for the 10:-1 ratio is

$C_{\mathrm{X}}=C_{\mathrm{N}}\left(\frac{1-t}{t}\right)\left(1+\Delta_{g}\right)$,

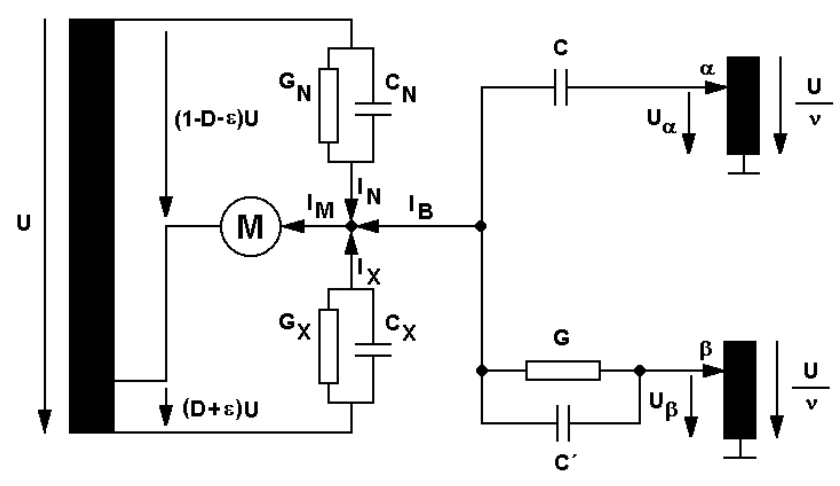

Figure 4. Simplified scheme of the capacitance bridge. 
where

$$
t=D+k^{\prime}
$$$$
\Delta_{g}=\Delta_{C}+\Delta_{C^{\prime}}+\Delta_{k^{\prime \prime}}
$$$$
\Delta_{C}=\frac{C}{C_{\mathrm{N}}}\left(\frac{\alpha}{v(1-t)}\right)
$$

$$
\Delta_{C^{\prime}}=\frac{C^{\prime}}{C_{\mathrm{N}}}\left(\frac{\beta}{v(1-t)}\right)
$$

$$
\Delta_{k^{\prime \prime}}=-\frac{k^{\prime \prime}}{t(1-t)}\left(\tan \delta_{\mathrm{N}}+\frac{\beta G}{\omega v C_{\mathrm{N}}}\right)
$$

where $\tan \delta_{\mathrm{N}}$ is the loss tangent of the standard capacitor. Here it is neither possible nor necessary to use the aforementioned cabling reversal technique. One needs however to know accurately the in-phase ratio error of the main IVD for the nominal ratio $D=1 / 11$. Thus, the main IVD needs to be calibrated at this ratio (see section 6).

The physical arrangement of the bridge is the same for both the 10:-1 and 1:-10 bridge ratios. The only change is the reversed position of $C_{\mathrm{N}}$ and $C_{\mathrm{X}}$. The balance equation for the 1:-10 ratio is

$$
C_{\mathrm{X}}=\frac{1}{1-t}\left[t C_{\mathrm{N}}-\frac{1}{v}\left(\alpha C+\beta C^{\prime}\right)+\frac{k^{\prime \prime}}{1-t}\left(C_{\mathrm{N}} \operatorname{tg} \delta_{\mathrm{N}}-\frac{\beta G}{\omega v}\right)\right] \text {. }
$$

\section{CABLE CORRECTION}

The values of $C_{X}$ obtained in (1), (5) and (6) include the cable parasitic contributions. We must correct the results for the cable errors. A simplified scheme of the capacitance bridge with the connecting cables modelled as delta networks is shown in Figure 5. Cable losses can be neglected for capacitance bridges as high quality cables are used.

$L_{1}$ and $C_{2}$ are, respectively, the inductance and half the capacitance of the cable labelled '(7)' in Figure 2. $L_{3}$ and $C_{6}$ are, respectively, the inductance and half the capacitance of the cable labelled '(8)'. The contribution of $C_{1}$ (and $C_{5}$ ) is not taken into account since these capacitances are in parallel with the source. The contribution of $C_{4}$ (and $C_{8}$ ) is negligible when the bridge is balanced. $L_{2}$ and $C_{3}$ are, respectively, the inductance and one-fourth the capacitance of the cable labelled '(9)' in Figure 2. $L_{4}$ and $C_{7}$ are, respectively, the inductance and onefourth the capacitance of the cable labelled '(10)'. $C_{\mathrm{HG}}$ and $C_{\mathrm{LG}}$ are the parasitic capacitances to ground of the high and low inputs of the standard capacitor $C_{\mathrm{N}}$, respectively. $C_{\mathrm{HG}}^{\prime}$ and $C_{\mathrm{LG}}^{\prime}$ are the capacitances to ground of the high and low inputs

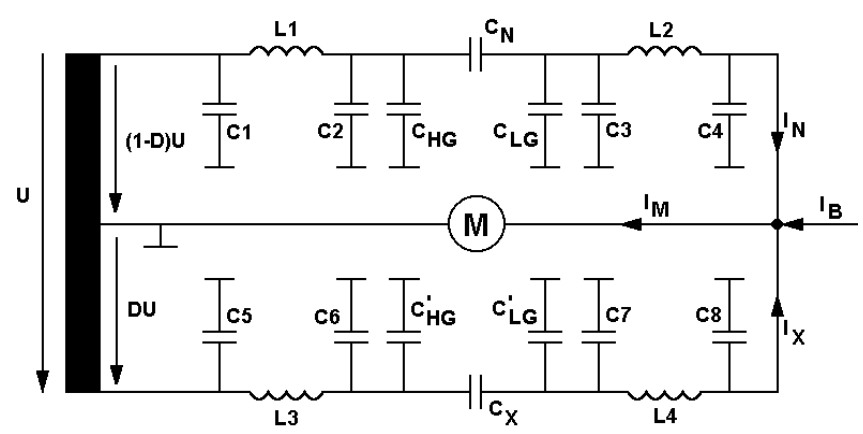

Figure 5. Simplified scheme of the capacitance bridge with cable modeling. of the capacitor under calibration $C_{\mathrm{X}}$, respectively.

The cable relative error for the standard capacitor is, approximately,

$$
\varepsilon_{\mathrm{RN}}=\frac{C_{\mathrm{TN}}-C_{\mathrm{N}}}{C_{\mathrm{N}}} \approx \omega^{2}\left[L_{1}\left(C_{\mathrm{N}}+C_{2 \mathrm{HG}}\right)+L_{2}\left(C_{\mathrm{N}}+C_{3 \mathrm{LG}}\right)\right],(7)
$$

where $C_{\mathrm{TN}}$ is the total capacitance of the standard capacitor (capacitor plus cables), $C_{2 \mathrm{HG}}=C_{2}+C_{\mathrm{HG}}$ and $C_{3 \mathrm{LG}}=C_{3}+C_{\mathrm{LG}}$. The cable relative error for the capacitor under calibration is, approximately,

$$
\varepsilon_{\mathrm{RX}}=\frac{C_{\mathrm{TX}}-C_{\mathrm{X}}}{C_{\mathrm{X}}} \approx \omega^{2}\left[L_{3}\left(C_{\mathrm{X}}+C_{6 \mathrm{HG}}^{\prime}\right)+L_{4}\left(C_{\mathrm{X}}+C_{7 \mathrm{LG}}^{\prime}\right)\right] \text {, }
$$

where $C_{\mathrm{TX}}$ is the total capacitance of the capacitor under calibration (capacitor plus cables), $C_{6 \mathrm{HG}}^{\prime}=C_{6}+C_{\mathrm{HG}}^{\prime}$ and $C_{7 \mathrm{LG}}^{\prime}=C_{7}+C_{\mathrm{LG}}^{\prime}$.

For the 1:-1 ratio, the measurement result should be corrected for the total relative error, that is, $\varepsilon_{\mathrm{R}}=\varepsilon_{\mathrm{RN}}-\varepsilon_{\mathrm{RX}}$.

For the 10:-1 ratio, we regard both the standard capacitor and its associated cable as a whole standard. The value of the standard capacitor is therefore inserted in the spreadsheet as $C_{\mathrm{N}}\left(1+\varepsilon_{\mathrm{RN}}\right)$, and the measurement result is corrected for the cable error of the capacitor under calibration, that is, $C_{\mathrm{X}}\left(1-\varepsilon_{\mathrm{RX}}\right)$.

\section{IVD DESIGN AND CONSTRUCTION}

A schematic diagram showing the arrangement of cores, windings and guarding of the main IVD is shown in Figure 6.

The IVD operates with up to $200 \mathrm{~V}$ (at $1 \mathrm{kHz}$ ) across the 0

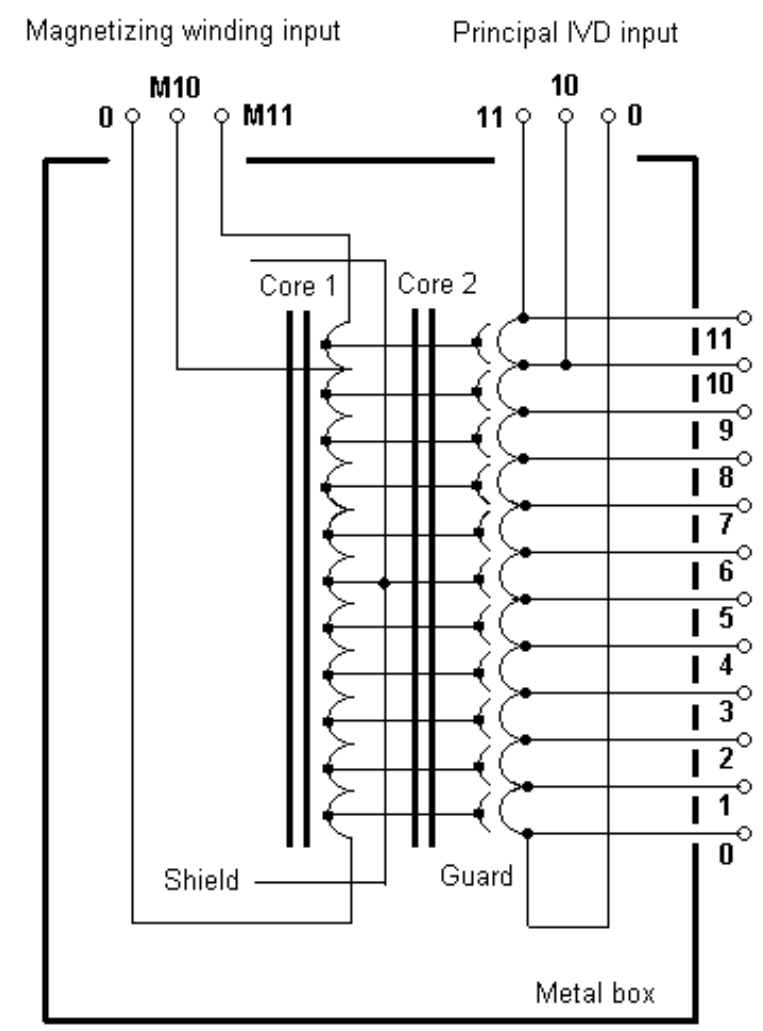

Figure 6. Schematic diagram showing the arrangement of cores, windings, and guarding (the grounding conductors are not shown for clarity). 


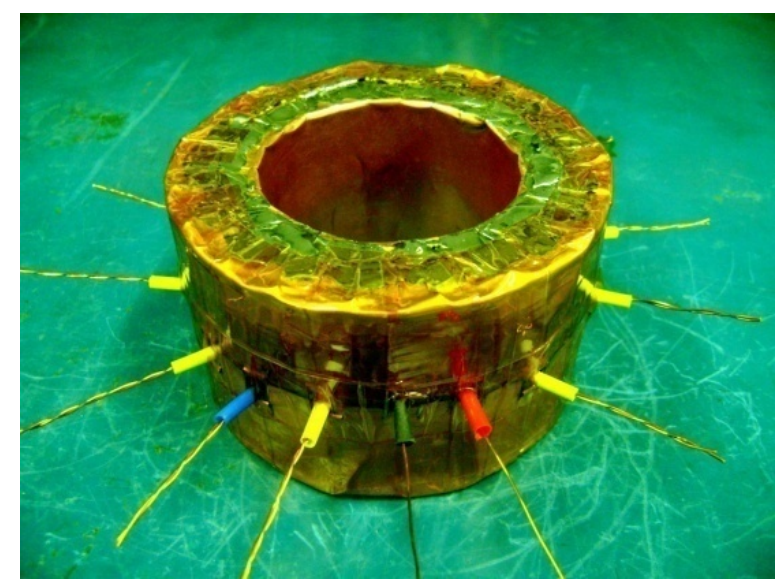

Figure 7. Shielded magnetizing winding with guard source taps.

and M10 taps. Therefore the first stage core comprises two plastic-encased supermalloy toroidal cores with $76.2 \mathrm{~mm}$ inner dia. x $101.6 \mathrm{~mm}$ outer dia. x $25.4 \mathrm{~mm}$ height and $0.0254 \mathrm{~mm}$ tape thickness (Magnetics 01500441F) placed one on top of the other. (Note: the previous design described in [8] used aluminium-encased cores).

A uniform one-layer 220-turn (with $0.57 \mathrm{~mm}$ dia. magnet wire) magnetizing winding covers the entire first stage core. This winding has three main taps for external connection whose leads are coloured for easy identification, namely, 0 (red), M10 (blue) and M11 (black), which are equivalent to ratios 0, 1.0 and 1.1, respectively. The guard source for the divider winding is obtained by tapping the magnetizing winding at appropriate points (yellow). The guard source taps are equally spaced around the core (arranged in a star configuration - see Figure 7). The guard voltages are $0.05 \mathrm{~V}, 0.15 \mathrm{~V}, 0.25 \mathrm{~V}, \ldots$, $1.05 \mathrm{~V}$ (assuming $1 \mathrm{~V}$ input).

The magnetizing winding is covered with kapton tape (an insulating tape with good electrical, mechanical and thermal properties) and enclosed in a soldered toroidal shield made of $0.1 \mathrm{~mm}$ copper foil (Figure 7). Care should be taken in the shield overlaps to avoid the shorted turn. The shield is set at mid-tap potential, i.e. connected to the magnetizing winding tap corresponding to 0.55 ratio (see Figure 6).

The cross-sectional area of the second stage core was chosen so that it has a magnetic permeance of about $1 / 3$ that of the first stage core. Therefore two plastic-encased supermalloy toroidal cores with dimensions $76.2 \mathrm{~mm}$ inner dia. $\mathrm{x} 95.3 \mathrm{~mm}$

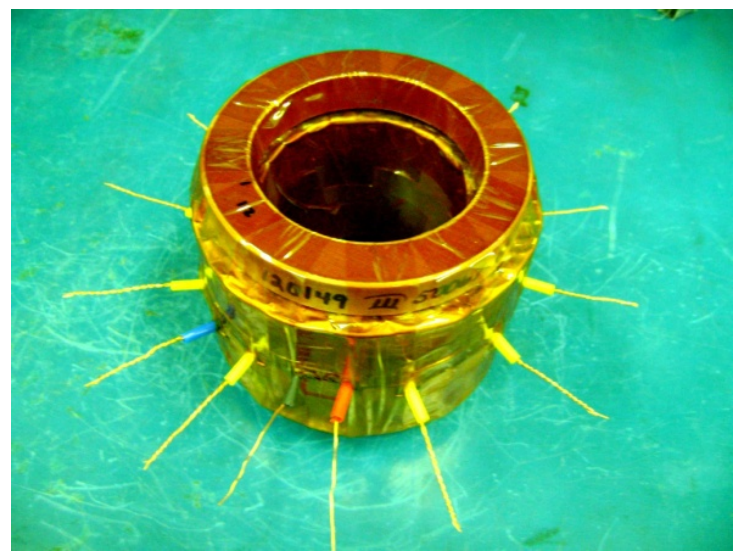

Figure 8. Shielded magnetizing winding with second stage cores (a second stage core is located below the assembly and cannot be seen).

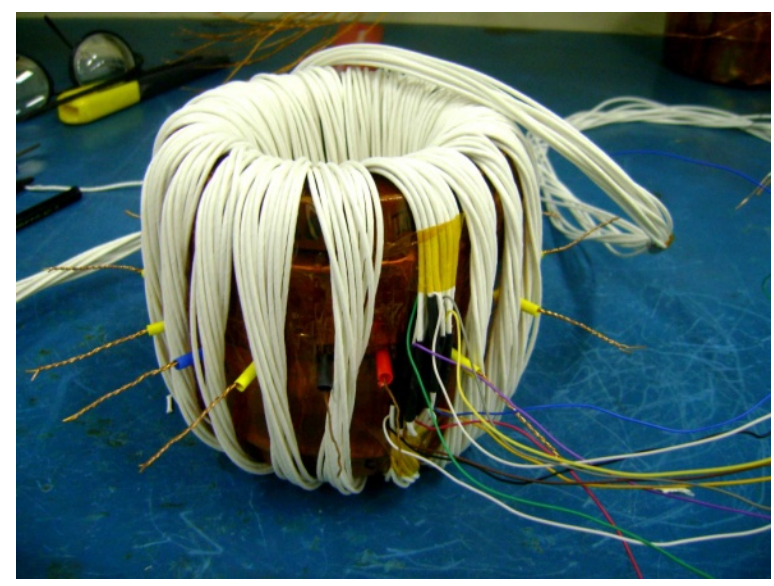

Figure 9. Ratio winding (rope arrangement).

outer dia. x $9.5 \mathrm{~mm}$ height and $0.0254 \mathrm{~mm}$ tape thickness (Magnetics 01500671F) were chosen. One core is placed on top of the shielded magnetizing winding and the other below it (Figure 8). This symmetric arrangement was chosen to minimize leakage fields. (Note: both the first and the second stage cores had been enclosed together within the toroidal shield in the design described in [8]).

The IVD ratio winding consists of a 20-turn rope of 11 coaxial cables wound around the core assembly whose ends are connected in series to create a 220-turn winding (Figure 9). (Note: here lies another difference from the previous design: a rope arrangement of the cables had not been employed in [8]). The tapped terminals 1 ... 10 are brought out from these interconnections (see Figure 6). The centre conductor is tapped at ten points, which are equivalent to ratios $0.1,0.2,0.3 \ldots 1$. The outer shield of the cable is cut (and insulated) at each tap. In this type of construction each section has the same resistance and is equally well coupled to all other sections, thus balancing the mutual and leakage impedances.

Before arranging the cables in a rope, a coloured wire is soldered as accurately as possible to the middle of the outer conductor of each coaxial cable (Figure 10). The whole assembly is then insulated with glass-fiber tape and the separate wires are connected to the corresponding magnetizing winding taps (Figure 11). Coloured wires are used to ensure that each wire is being connected to the correct guard tap. We confirmed that mistakes here are common and always result in large IVD ratio errors. This guarding method is an attempt to equalize the admittances between each half of each guard and nearby

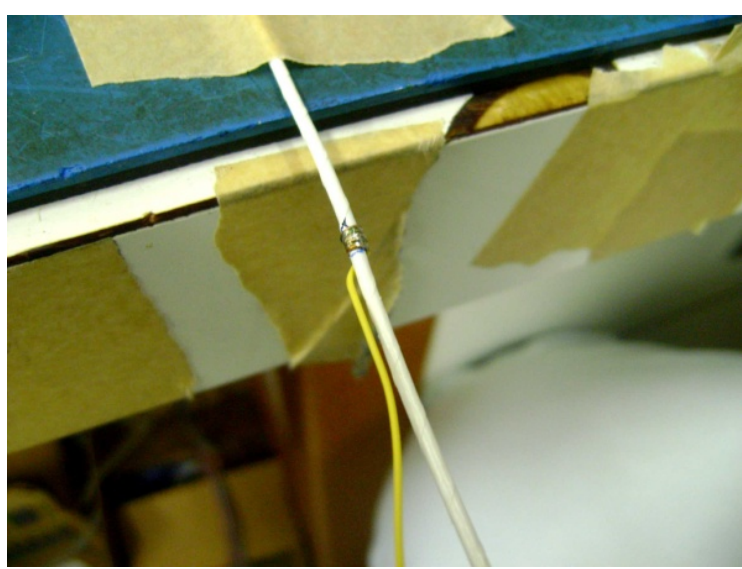

Figure 10. A wire soldered to the middle of the outer conductor. 


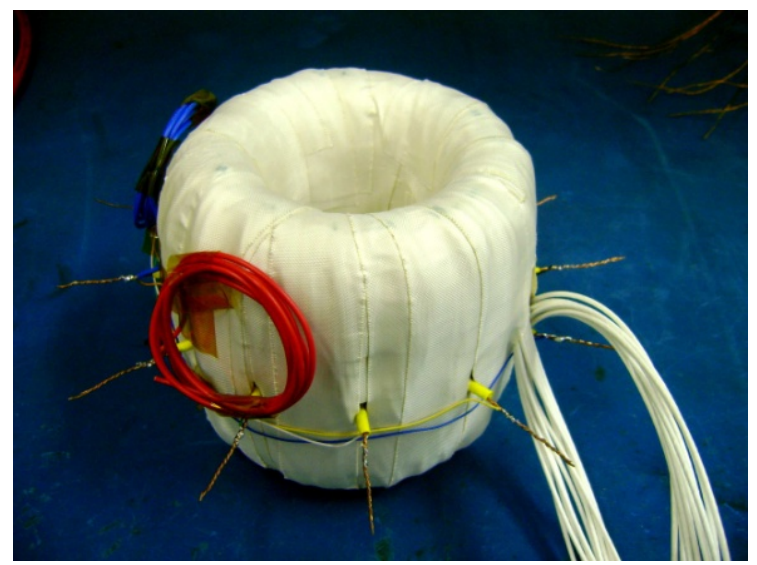

Figure 11. Separate wires connected to the magnetizing winding taps.

conductors.

The coaxial cable is GORE GSC 6591 (conductor size: 19 x $0.127 \mathrm{~mm}$ AWG 24 (19/36), $0.24 \mathrm{~mm}^{2}$; conductor material: $\mathrm{CuAg}, 78.5 \mathrm{~m} \Omega / \mathrm{m}$; dielectric diameter: $0.84 \mathrm{~mm}$; dielectric material: PTFE; screen details: braided screen from $\mathrm{CuAg}$ AWG 38 (1); jacket material: $0.15-\mathrm{mm}$ PTFE; nominal diameter: $1.6 \mathrm{~mm}$.).

The whole assembly is then insulated with kapton tape, isolated from mechanical vibrations (with $25 \mathrm{~mm}$ extruded polystyrene slabs fixed by two opposing insulating boards kept firm with four aluminium rods) and enclosed in a metal box with holes on its top panel for later penetration of the coaxial output sockets (Figure 12).

The method of bringing out the taps to the coaxial connectors requires consideration if the highest possible accuracy is to be attained. The coaxial output sockets (BPO connectors) are fixed to a rigid insulating board placed above the IVD assembly (Figure 13). They are insulated from the metal box in Figure 14. Stout conductors $(1.3 \mathrm{~mm}$ dia. magnet wire) are taken from the socket outers for the IVD ratio winding, routing them close to the short tap connections to a point well within the volume of the box where they are joined together (see Figure 12). This point is grounded to the metal box through an output socket. The electrical resistance between each socket outer and the metal box was measured to be less than $0.015 \Omega$.

The same arrangement for bringing out the taps to the

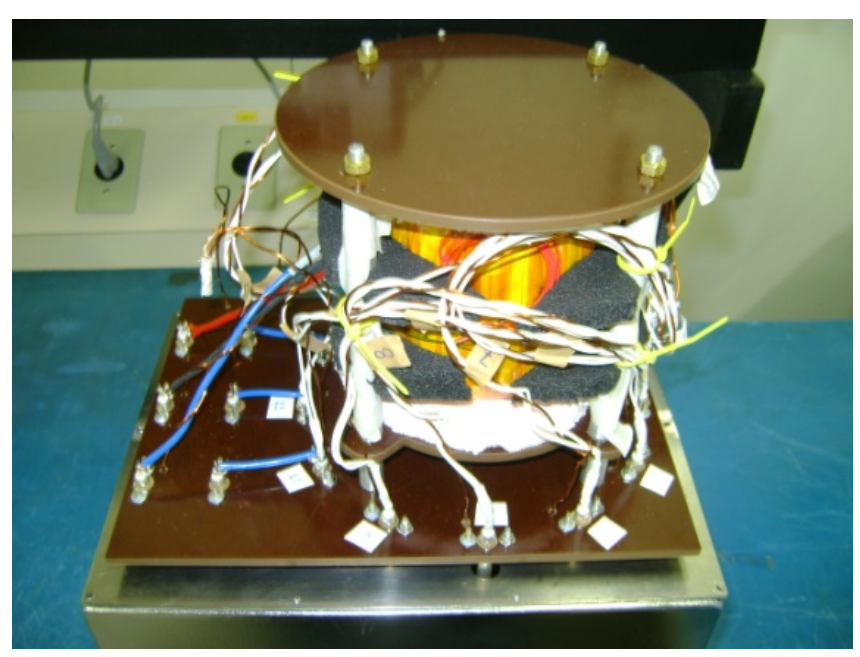

Figure 12. The whole assembly is isolated from mechanical vibrations.

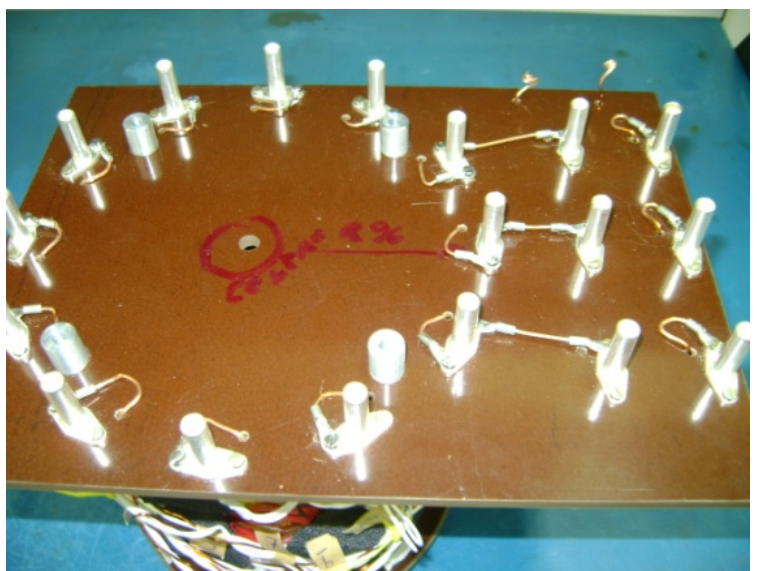

Figure 13. Coaxial output sockets (BPO connectors).

coaxial connectors is adopted for the IVD magnetizing winding leads. The joint point of the stout conductors is also grounded to the metal box through another output socket. The resistance between each socket outer and the metal box was measured to be less than $0.009 \Omega$. The BPO connectors for the magnetizing winding are the three ones located on the right side of Figure 13. See [4] for more details on this grounding arrangement.

The metal box is made of $1.5 \mathrm{~mm}$ chromium-coated carbon steel and the box inner surface is covered with $0.79 \mathrm{~mm}$ mumetal sheets. The box panel has the following outputs: (a) divider taps: 0 (twofold), 1, 2, 3, 4, 5, 6, 7, 8, 9, 10 (twofold), and 11 (twofold), (b) magnetizing winding taps: 0, M10 and M11, and (c) two independent ground connections (both the magnetizing winding and the ratio winding stout conductor joint points were always grounded to the metal box in the IVD calibration and capacitance bridge measurements - see Figure 2 for grounding connections). The final assembly of the main IVD is shown in Figure 14. The short-circuiting plugs of the two independent ground connections are not shown in the figure.

\section{IVD CALIBRATION}

As remarked in section 2, one needs to know accurately the in-phase ratio error of the main IVD for the nominal ratio $D=$ $1 / 11$. The ratio error of the new main IVD was therefore calibrated at Inmetro. The old IVD was replaced by the new one in the coaxial capacitance bridge and the bridge was used to

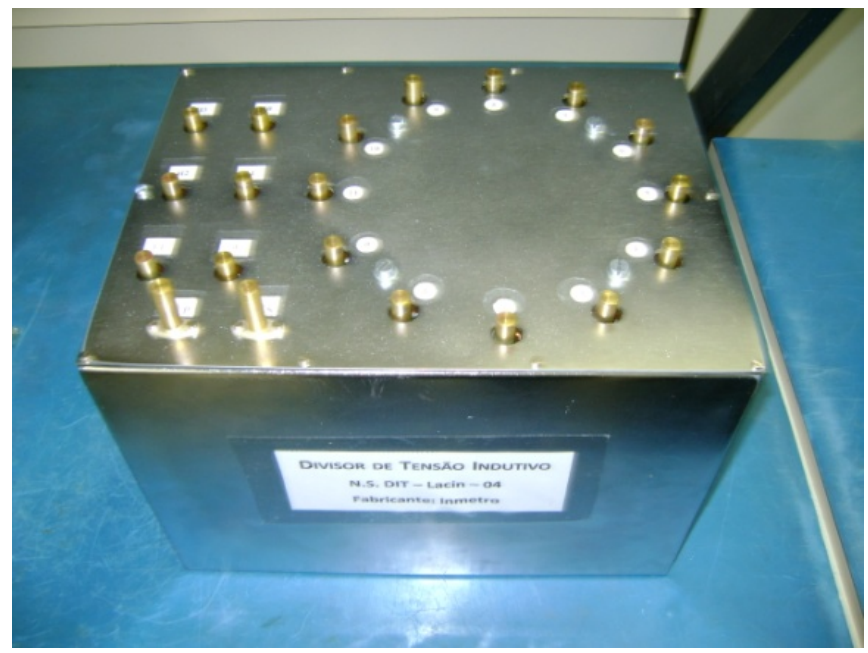

Figure 14. Main IVD final assembly. 
compare $10 \mathrm{pF}$ and $100 \mathrm{pF}$ fused-silica standard capacitors which had been previously calibrated by the Bureau International des Poids et Mesures (BIPM) with a relative uncertainty of 4 parts in $10^{8}$. With this method one can only measure the in-phase component of the complex ratio error. The calibration was performed at $110 \mathrm{~V}$ (across the 0 and M11 taps) and at both $1 \mathrm{kHz}$ and $1.592 \mathrm{kHz}$.

The dividing factors $\alpha$ and $\beta$ in (5) can be expressed as

$\alpha=\bar{\alpha}+R_{\alpha}+\sigma_{\alpha}$

$\beta=\bar{\beta}+\mathrm{R}_{\beta}+\sigma_{\beta}$,

where $\bar{\alpha}$ and $\bar{\beta}$ are the values, $R_{\alpha}$ and $R_{\beta}$ are the resolutions and $\sigma_{\alpha}$ and $\sigma_{\beta}$ are the random deviations of the $\alpha$ and $\beta$ readings, respectively.

Neglecting the contribution from $\Delta_{k}$, in (5), and rearranging terms, the IVD ratio can be expressed as

$t=\frac{C_{\mathrm{N}}+A}{C_{\mathrm{N}}+C_{\mathrm{X}}}$,

where

$A=\frac{1}{v}\left(C \alpha+C^{\prime} \beta\right)$.

The values of $C_{\mathrm{N}}$ and $C_{\mathrm{X}}$ in (10) include their drifts with time and the cable parasitic contributions, that is

$C_{\mathrm{N}}=\bar{C}_{\mathrm{N}}\left(1+\varepsilon_{\mathrm{RN}}\right)+d_{\mathrm{N}}$

$C_{\mathrm{X}}=\bar{C}_{\mathrm{X}}\left(1-\varepsilon_{\mathrm{RX}}\right)+d_{\mathrm{X}}$,

where $\bar{C}_{\mathrm{N}}$ and $\bar{C}_{\mathrm{X}}$ are the capacitance values reported in the calibration certificate, $\varepsilon_{\mathrm{RN}}$ and $\varepsilon_{\mathrm{RX}}$ are the relative corrections of the cables connected to each capacitor according to (7) and (8), and $d_{\mathrm{N}}$ and $d_{\mathrm{x}}$ are the capacitor drifts in the period between the date the capacitor calibration certificates were issued by BIPM and the date of the IVD calibration. We regard both the standard capacitor and its associated cable as a whole standard. The value of $C_{\mathrm{N}}$ is therefore inserted in the spreadsheet as $C_{\mathrm{N}}(1$ $\left.+\varepsilon_{\mathrm{RN}}\right)$ and the value of $C_{\mathrm{X}}$ is inserted in the spreadsheet as $C_{\mathrm{X}}\left(1-\varepsilon_{\mathrm{RX}}\right)$.

Since the main uncertainty contributions to the cable error are associated with the parasitic inductances and capacitances of the capacitor and cable, we may neglect the uncertainty contribution associated with the capacitor values and write

$C_{\mathrm{N}}=\bar{C}_{\mathrm{N}}+\delta C_{\mathrm{N}}+d_{\mathrm{N}}$

$C_{\mathrm{X}}=\bar{C}_{\mathrm{X}}-\delta C_{\mathrm{X}}+d_{\mathrm{X}}$,

where $\delta C_{\mathrm{N}}$ and $\delta C_{\mathrm{X}}$ are the absolute corrections of the cable errors (in $\mathrm{F}$ ), that is

$$
\begin{aligned}
& \delta C_{\mathrm{N}} \approx \omega^{2} C_{\mathrm{N}}\left[L_{1}\left(C_{\mathrm{N}}+C_{2 \mathrm{HG}}\right)+L_{2}\left(C_{\mathrm{N}}+C_{3 \mathrm{LG}}\right)\right], \\
& \delta C_{\mathrm{X}} \approx \omega^{2} C_{\mathrm{X}}\left[L_{3}\left(C_{\mathrm{X}}+C_{6 \mathrm{HG}}^{\prime}\right)+L_{4}\left(C_{\mathrm{X}}+C_{7 \mathrm{LG}}^{\prime}\right)\right] .
\end{aligned}
$$

Here $C_{\mathrm{N}}=10 \mathrm{pF}$ and $C_{\mathrm{X}}=100 \mathrm{pF}$, and it is assumed that their contributions to the uncertainty associated with $\delta C_{\mathrm{N}}$ and $\delta C_{\mathrm{X}}$ are negligible.

The in-phase component of the main IVD ratio error is estimated from
$k^{\prime}=t-D$

By taking into account that the variables $\bar{C}_{\mathrm{N}}$ and $\bar{C}_{\mathrm{X}}$ are strongly correlated as the capacitors were calibrated at BIPM with the same system, that is

$$
u\left(\bar{C}_{\mathrm{N}}, \bar{C}_{\mathrm{X}}\right) \neq 0 \quad \Rightarrow \quad u\left(C_{\mathrm{N}}, C_{\mathrm{X}}\right) \neq 0
$$

the squared standard uncertainty associated with that estimate is then [14]

$$
\begin{aligned}
u^{2}\left(k^{\prime}\right)= & u^{2}(t)=\frac{\left(C_{\mathrm{X}}-A\right)^{2}}{\left(C_{\mathrm{N}}+C_{\mathrm{X}}\right)^{4}} \cdot u^{2}\left(C_{\mathrm{N}}\right) \\
& +\frac{\left(C_{\mathrm{N}}+A\right)^{2}}{\left(C_{\mathrm{N}}+C_{\mathrm{X}}\right)^{4}} \cdot u^{2}\left(C_{\mathrm{X}}\right) \\
& +\frac{1}{\left(C_{\mathrm{N}}+C_{\mathrm{X}}\right)^{2}} \cdot u^{2}(A) \\
& -2 \cdot \frac{\left(C_{\mathrm{X}}-A\right)\left(C_{\mathrm{N}}+A\right)}{\left(C_{\mathrm{N}}+C_{\mathrm{X}}\right)^{4}} \cdot u\left(C_{\mathrm{N}}, C_{\mathrm{X}}\right)
\end{aligned}
$$

where

$$
\begin{aligned}
u^{2}\left(C_{\mathrm{N}}\right)= & u^{2}\left(\bar{C}_{\mathrm{N}}\right)+u^{2}\left(\delta C_{\mathrm{N}}\right)+u^{2}\left(d_{\mathrm{N}}\right) \\
u^{2}\left(C_{\mathrm{X}}\right)= & u^{2}\left(\bar{C}_{\mathrm{X}}\right)+u^{2}\left(\delta C_{\mathrm{X}}\right)+u^{2}\left(d_{\mathrm{X}}\right) \\
u^{2}\left(\delta C_{\mathrm{N}}\right)= & \omega^{2} C_{\mathrm{N}}^{2} u^{2}\left(L_{1}\right)+\omega^{2} C_{\mathrm{N}} u^{2}\left(C_{2 \mathrm{HG}}\right) \\
& +\omega^{2} C_{\mathrm{N}}^{2} u^{2}\left(L_{2}\right)+\omega^{2} C_{\mathrm{N}} u^{2}\left(C_{3 \mathrm{LG}}\right) \\
u^{2}\left(\delta C_{\mathrm{X}}\right)= & \omega^{2} C_{\mathrm{X}}^{2} u^{2}\left(L_{3}\right)+\omega^{2} C_{\mathrm{X}} u^{2}\left(C_{6 \mathrm{HG}}^{\prime}\right) \\
& +\omega^{2} C_{\mathrm{X}}^{2} u^{2}\left(L_{4}\right)+\omega^{2} C_{\mathrm{X}} u^{2}\left(C_{7 \mathrm{LG}}^{\prime}\right) \\
u^{2}(A)= & \frac{1}{v^{2}}\left[C^{2} u^{2}(\alpha)+\alpha^{2} \cdot u^{2}(C)\right. \\
& \left.+C^{\prime 2} u^{2}(\beta)+\beta^{2} u^{2}\left(C^{\prime}\right)\right] \\
& +\frac{1}{v^{4}} \cdot\left(C \alpha+C^{\prime} \beta\right)^{2} u^{2}(v) \\
u^{2}(\alpha)= & u^{2}(\bar{\alpha})+u^{2}\left(R_{\alpha}\right)+u^{2}\left(\sigma_{\alpha}\right) \\
u^{2}(\beta)= & u^{2}(\bar{\beta})+u^{2}\left(\mathrm{R}_{\beta}\right)+u^{2}\left(\sigma_{\beta}\right) \\
u\left(C_{\mathrm{N}}, C_{\mathrm{X}}\right)= & u\left(\bar{C}_{\mathrm{N}}, \bar{C}_{\mathrm{X}}\right)=u\left(\bar{C}_{\mathrm{N}}\right) \cdot u\left(\bar{C}_{\mathrm{X}}\right)
\end{aligned}
$$

since a correlation $\rho\left(\bar{C}_{\mathrm{N}}, \bar{C}_{\mathrm{X}}\right)=1$ is assumed here. The above uncertainty contributions were evaluated according to [14].

The in-phase 10:-1 ratio errors $k^{\prime}$ and their expanded uncertainties $U\left(k^{\prime}\right)$, evaluated respectively with (15) and (17), are listed in Table 4. Table 5 lists the in-phase and quadrature 1:-1 ratio errors evaluated from (4).

The old IVD whose construction was reported in [8] was calibrated again using the same method described here. The reader should compare the results listed in Tables 6 and 7 with those for the new IVD.

The ratio errors of the new IVD are indeed much smaller than those of the old one. 


\section{CAPACITANCE BRIDGE MEASUREMENT UNCERTAINTY}

The new IVD was installed in the two terminal-pair coaxial capacitance bridge and the uncertainty obtained in capacitance calibration was assessed again here. This bridge has been used for calibrating stable standard capacitors at Inmetro since its construction in 2005.

An experiment was made to evaluate the consistency of the measurement results obtained with this bridge. Consider three $10 \mathrm{pF}$ fused-silica standard capacitors labelled here for convenience as A, B, and C. Capacitor A is traceable to BIPM. Firstly, capacitor B was calibrated by comparing it with known capacitor A. Secondly, capacitor C was similarly calibrated and the (computed) difference between $\mathrm{B}$ and $\mathrm{C}$ values was recorded. Capacitor B (assuming it to be unknown) was then calibrated by comparing it with the (now) known capacitor $\mathrm{C}$ and the (measured) difference between $\mathrm{B}$ and $\mathrm{C}$ values was also recorded. All measurement results were corrected for cable errors. The computed and measured differences between $\mathrm{B}$ and $\mathrm{C}$ values differed by $7 \times 10^{-10}$ at $1.592 \mathrm{kHz}$ when the new IVD was installed in the bridge. Contrast this with the $6.7 \times 10^{-9}$ figure obtained when the old IVD was installed in the bridge (or even with the $1.5 \times 10^{-8}$ figure reported earlier in [6]). This is a bridge systematic error which is detected when comparing several standards of same nominal value for consistency in the results. This error contributes to the overall uncertainty of the bridge at 1:-1 ratio. So, this uncertainty contribution was reduced by one order of magnitude as a result of the reduced ratio errors presented by the new IVD.

Table 8 shows the uncertainty budget for the calibration at 1:-1 ratio and at $1.592 \mathrm{kHz}$ of a stable $10 \mathrm{pF}$ fused-silica standard capacitor $\left(C_{\mathrm{X}}\right)$ from a similar capacitor $\left(C_{\mathrm{N}}\right)$ traceable to BIPM. The combined relative standard uncertainty associated with the difference between the capacitance values of the standards being compared $\left(C_{\mathrm{X}}-C_{\mathrm{N}}\right)$ is less than one part in $10^{8}$. The uncertainty contribution due to the capacitance bridge is therefore negligible compared to other contributions such as

Table 4. In-phase 10:-1 ratio errors (new IVD).

\begin{tabular}{ccc}
\hline Frequency $(\mathbf{H z})$ & $\boldsymbol{k}^{\prime}$ & $\boldsymbol{U}\left(\boldsymbol{k}^{\prime}\right)$ \\
\hline 1000 & $3 \times 10^{-9}$ & $23 \times 10^{-9}$ \\
1592 & $12 \times 10^{-9}$ & $23 \times 10^{-9}$ \\
\hline
\end{tabular}

Table 5. In-phase and quadrature 1:-1 ratio errors (new IVD).

\begin{tabular}{ccc}
\hline Frequency $(\mathrm{Hz})$ & $\boldsymbol{k}^{\prime}$ & $\boldsymbol{k}^{\prime \prime}$ \\
\hline 1592 & $23 \times 10^{-9}$ & $9 \times 10^{-9}$ \\
\hline
\end{tabular}

Table 6. In-phase 10:-1 ratio errors (old IVD).

\begin{tabular}{ccc}
\hline Frequency $(\mathrm{Hz})$ & $\boldsymbol{k}^{\prime}$ & $\boldsymbol{U}\left(\boldsymbol{k}^{\prime}\right)$ \\
\hline 1000 & $-124 \times 10^{-9}$ & $23 \times 10^{-9}$ \\
1592 & $-164 \times 10^{-9}$ & $23 \times 10^{-9}$ \\
\hline
\end{tabular}

Table 7. In-phase and quadrature 1: -1 ratio errors (old IVD).

\begin{tabular}{ccc}
\hline Frequency $(\mathrm{Hz})$ & $\boldsymbol{k}^{\prime}$ & $\boldsymbol{k}^{\prime \prime}$ \\
\hline 1592 & $-280 \times 10^{-9}$ & $23 \times 10^{-9}$ \\
\hline
\end{tabular}

Table 8. Uncertainty budget at 1:-1 ratio (10 pF $-1.592 \mathrm{kHz})$.

\begin{tabular}{|c|c|c|c|}
\hline Quantity & $\begin{array}{c}\text { Standard } \\
\text { uncertainty }\end{array}$ & $\begin{array}{l}\text { Sensitivity } \\
\text { coefficient }\end{array}$ & $\begin{array}{l}\text { Eval. } \\
\text { Type }\end{array}$ \\
\hline$C_{N}{ }^{(1)}$ & $4.0 \times 10^{-7} \mathrm{pF}$ & 1 & B \\
\hline$\Delta \alpha$ & $3.16 \times 10^{-6}$ & $1.00 \times 10^{-2} \mathrm{pF}$ & $A$ \\
\hline$\Delta \beta$ & $7.48 \times 10^{-7}$ & $8.00 \times 10^{-6} \mathrm{pF}$ & $A$ \\
\hline C & $4 \times 10^{-8} \mathrm{pF}$ & $6.56 \times 10^{-5}$ & B \\
\hline$C^{\prime}$ & $0.0008 \mathrm{pF}$ & $8.00 \times 10^{-7}$ & B \\
\hline$v$ & 0.1 & $6.63 \times 10^{-7} \mathrm{pF}$ & B \\
\hline$\varepsilon_{\mathrm{R}}^{(2)}$ & $1 \times 10^{-8} \mathrm{pF}$ & 1 & B \\
\hline$C_{\mathrm{X}}-C_{\mathrm{N}}^{(3)}$ & $7 \times 10^{-8} \mathrm{pF}$ & 1 & Comb. \\
\hline Error ${ }^{(4)}$ & $7 \times 10^{-9} \mathrm{pF}$ & 1 & B \\
\hline$C_{\mathrm{x}}{ }^{(5)}$ & $7 \times 10^{-8} \mathrm{pF}$ & 1 & Comb. \\
\hline$R_{\mathrm{K}-90}{ }^{(6)}$ & $1.00 \times 10^{-6} \mathrm{pF}$ & 1 & B \\
\hline Biannual Drift ${ }^{(7)}$ & $1.00 \times 10^{-6} \mathrm{pF}$ & 1 & A \\
\hline$C_{X}^{(8)}$ & $1.5 \times 10^{-6} \mathrm{pF}$ & & Comb. \\
\hline
\end{tabular}

(1) Relative combined standard uncertainty reported in the BIPM calibration certificate for $C_{\mathrm{N}}$ (a $10 \mathrm{pF}$ capacitor).

(2) Uncertainty contribution associated with the correction for the cable errors.

(3) Combined standard uncertainty associated with the difference between the capacitances of the standards being compared (see text).

(4) Systematic error that is detected when comparing several standards for consistency in the results (see text).

(5) Combined standard uncertainty associated with $C_{\mathrm{X}}$ without taking into account the uncertainty contributions associated with $R_{\mathrm{K}-90}$ and the reference standard biannual drift. $C_{\mathrm{X}}$ is a $10 \mathrm{pF}$ capacitor.

(6) Standard uncertainty associated with the recommended value of $R_{K-90}$.

(7) Biannual drift evaluated by fitting a straight line to data reported in BIPM calibration certificates in the last six years.

(8) Combined standard uncertainty associated with $C_{\mathrm{X}}$ by taking into account all known uncertainty contributions.

Table 9. Uncertainty budget at 10:-1 ratio (100 pF - $1.592 \mathrm{kHz})$.

\begin{tabular}{cccc}
\hline Quantity & Standard uncertainty & $\begin{array}{c}\text { Sensitivity } \\
\text { coefficient }\end{array}$ & $\begin{array}{c}\text { Eval. } \\
\text { Type }\end{array}$ \\
\hline$C_{\mathrm{N}}{ }^{(1)}$ & $4.0 \times 10^{-7} \mathrm{pF}$ & 10 & $\mathrm{~B}$ \\
$\alpha$ & $1.5 \times 10^{-6}$ & $1.00 \times 10^{-1} \mathrm{pF}$ & $\mathrm{A}$ \\
$k^{\prime}$ & $1.2 \times 10^{-8}$ & $-1.21 \times 10^{3} \mathrm{pF}$ & $\mathrm{B}$ \\
$\mathcal{E}_{\mathrm{R}}{ }^{(2)}$ & $1 \times 10^{-8} \mathrm{pF}$ & 1 & $\mathrm{~B}$ \\
$C_{\mathrm{X}}{ }^{(3)}$ & $1.51 \times 10^{-5} \mathrm{pF}$ & 1 & $\mathrm{Comb}$ \\
$R_{\mathrm{K}-90}{ }^{(4)}$ & $1.00 \times 10^{-5} \mathrm{pF}$ & 1 & $\mathrm{~B}$ \\
Biannual Drift ${ }^{(5)}$ & $1.00 \times 10^{-5} \mathrm{pF}$ & 1 & $\mathrm{~A}$ \\
$C_{\mathrm{X}}{ }^{(6)}$ & $2.1 \times 10^{-5} \mathrm{pF}$ & & Comb.
\end{tabular}

(1) Relative combined standard uncertainty reported in the BIPM calibration certificate for $C_{\mathrm{N}}$ (a $10 \mathrm{pF}$ capacitor).

(2) Uncertainty contribution associated with the correction for the cable errors.

(3) Combined standard uncertainty associated with $C_{\mathrm{X}}$ without taking into account the uncertainty contributions associated with $R_{K-90}$ and the reference standard biannual drift. $\mathrm{C}_{\mathrm{X}}$ is a $100 \mathrm{pF}$ capacitor.

(4) Standard uncertainty associated with the recommended value of $R_{K-90}$.

(5) Biannual drift evaluated by fitting a straight line to data reported in BIPM calibration certificates in the last six years.

(6) Combined standard uncertainty associated with $C_{\mathrm{X}}$ by taking into account all known uncertainty contributions. 
the relative uncertainty reported in the BIPM certificate, the reference standard drift, and the uncertainty associated with the recommended value of $R_{\mathrm{K}-90}$ (von Klitzing constant). The major uncertainty contributions are now the $1 / \mathrm{v}$ ratio and the stability of the $\Delta \alpha\left(=\alpha_{1}-\alpha_{2}\right)$ readings.

Table 9 shows the uncertainty budget for the calibration at 10:-1 ratio and at $1.592 \mathrm{kHz}$ of a stable $100 \mathrm{pF}$ fused-silica standard capacitor $\left(C_{\mathrm{X}}\right)$ from a similar $10 \mathrm{pF}$ capacitor $\left(C_{\mathrm{N}}\right)$ traceable to BIPM. The combined relative standard uncertainty associated with the calibration result (without the uncertainty contributions associated with $R_{\mathrm{K}-90}$ and with the reference standard drift) is $1.5 \times 10^{-7}$. The major contribution to the overall bridge uncertainty at the 10:-1 ratio is that associated with the in-phase component of the IVD ratio error.

As mentioned in the introduction, the main IVD to be used in coaxial ratio bridges should be constructed to provide an overall bridge uncertainty at 1:-1 and 10:-1 ratios of a few parts in $10^{8}$. In order to achieve this for the 10:-1 ratio it is necessary to reduce the uncertainty associated with the in-phase component of the IVD ratio error by one order of magnitude. This demands the construction of a special system for calibrating the IVD 10:-1 ratio with an uncertainty of a few parts in $10^{9}$.

Note: Quantities not listed in Tables 8 and 9 were found to have negligible uncertainty contributions.

\section{CONCLUSIONS}

The constructional details of the new main two-stage IVD for coaxial bridge applications, recently built at Inmetro, were presented along with the design changes implemented. The design changes are: (a) plastic-encased cores are used as first stage cores, (b) only the magnetizing winding and the first stage cores are copper shielded and (c) a rope arrangement is employed for the coaxial cables in the ratio winding. The method used to calibrate the IVD ratio error was also described in detail. The in-phase 10:-1 ratio error was determined from known values of two stable decadic standard capacitors.

It was confirmed that the ratio errors of the new IVD are much smaller than those reported previously for another IVD. Upon installing the new IVD in Inmetro's coaxial capacitance bridge, the major contributions to the overall uncertainty of the 1:-1 ratio bridge are those associated with the predivider ratio and with the stability of the readings. The major contribution at 10:-1 ratio is that associated with the in-phase component of the IVD ratio error. A special system for calibrating the IVD 10:-1 ratio with an uncertainty of a few parts in $10^{9}$ is required if one needs to achieve an overall uncertainty of parts in $10^{8}$ with the 10:-1 ratio bridge.

\section{ACKNOWLEDGEMENT}

G. K. thanks L. M. Ogino and E. Afonso for providing the resources for this project. G. K. also wishes to thank all Inmetro/Sengi personnel and the late A. Etchebehere for the construction of the IVD metal box. He also thanks
R. P. Miloski for soldering the IVD coaxial cables and R. T. B. Vasconcellos for previous collaboration in the construction and initial operation of the capacitance bridge.

\section{REFERENCES}

[1] J.Melcher, J.Schurr, "Modular system for the calibration of capacitance standards based on the quantum Hall effect", Proc. of V SEMETRO, 2002, Apr. 9-12, Rio de Janeiro, Brazil.

[2] J.Melcher, J.Schurr, K.Pierz et al., "The European ACQHE Project: modular system for the calibration of capacitance standards based on the quantum Hall effect", IEEE Trans. Instrum. Meas., Apr. 2003, 52, no.2, pp. 563-568.

[3] Physikalisch-Technische Bundesanstalt (PTB), J.Schurr, J.Melcher, "Modular System for the Calibration of Capacitance Standards Based on the Quantum Hall Effect," Workshop and Project Documentation, January 2002, Brauschweig, Germany. Available in CD-ROM.

[4] B.P.Kibble, G.H.Rayner, Coaxial AC Bridges, Adam Hilger Ltd., 1984.

[5] D.Homan, T.Zapf, "Two stage, guarded inductive voltage divider for use at $100 \mathrm{kHz}$ ", ISA Trans., 1970, 9, no. 3, pp. 201-209.

[6] G.A.Kyriazis, R.T.B.Vasconcellos, L.M.Ogino, J.Melcher, J.A.Moreno, "Design and construction of a two terminal-pair coaxial capacitance bridge", Proc. of VI SEMETRO, 2005, Sept. 21-23, Rio de Janeiro, Brazil, pp. 57-62.

[7] G.A.Kyriazis, R.T.B.Vasconcellos, L.M.Ogino, J.Melcher, J.A.Moreno, "A two terminal-pair coaxial capacitance bridge constructed at Inmetro", CPEM Digest, 2006, July 9-14, Turin, Italy, pp. 522-523.

[8] G.A.Kyriazis, J.Melcher, J.A.Moreno, "A two-stage, guarded inductive voltage divider for use in coaxial bridges employed in the derivation of the capacitance unit from quantized Hall resistance", CPEM Digest, 2004, June 27 - July 2, London, UK, pp. 131-132.

[9] J.A.Moreno, R.Hanke, "Maintenance and development of the capacitance unit at CENAM", CPEM Digest, 2000, May 14-19, Sydney, Australia, pp. 218-219.

[10] A.Koffman, N.F.Zhang, Y.Wang, S.Shields, B.Wood, K.Kochav, J.A.Moreno, H.Sanchez, B.I.Castro, M.Cazabat, L.M.Ogino, G.A.Kyriazis, R.T.B.Vasconcellos, D.Slomovitz, D.Izquierdo, C.Faverio, "SIM.EM-K4 capacitance comparison summary", CPEM Digest, 2012, July 1-6, Washington, DC, USA, pp. 398-399.

[11] G.A.Kyriazis, R.T.B.Vasconcellos, "Unequalized currents in two terminal-pair coaxial capacitance bridges", Proc. XVIII IMEKO World Congress, 2006, Sept. 17-22, Rio de Janeiro, Brazil.

[12] J.Schurr, J.Melcher, "Unequalized currents in coaxial ac bridges", IEEE Trans. Instrum. Meas., Jun. 2004, 53, no. 3, pp. 807-811.

[13] G.A.Kyriazis, L.M.Ogino, E.Afonso, J.A.Neves, "An isolation transformer for coaxial bridges used in the derivation of the capacitance unit from the ac quantized Hall resistance", MAPAN JMSI, Jul.-Sept. 2003, 18, no. 3, pp. 137-144.

[14] BIPM, IEC, IFCC, ILAC, ISO, IUPAC, IUPAP and OIML, Evaluation of measurement data - Guide to the Expression of Uncertainty in Measurement, GUM 1995 with minor corrections, Joint Committee for Guides in Metrology, JCGM 100, 2008, http://www.bipm.org/utils/common/documents/ jcgm/JCGM_100_2008_E.pdf (accessed 29.10.11). 